\title{
Mastectomy for management of breast cancer in Ibadan, Nigeria
}

Temidayo O Ogundiran ${ }^{1,2^{*}}$, Omobolaji O Ayandipo ${ }^{2}$, Adeyinka F Ademola ${ }^{1,2}$ and Clement A Adebamowo 3,4

\begin{abstract}
Background: Modified radical mastectomy remains the standard therapeutic surgical operation for breast cancer in most parts of the world. This retrospective study reviews mastectomy for management of breast cancer in a surgical oncology division over a ten year period.

Methods: We reviewed the case records of consecutive breast cancer patients who underwent mastectomy at the Surgical Oncology Division, University College Hospital (UCH) Ibadan between November 1999 and October 2009.

Results: Of the 1226 newly diagnosed breast cancer patients over the study period, 431 (35.2\%) patients underwent mastectomy making an average of 43 mastectomies per year. Most patients were young women, premenopausal, had invasive ductal carcinoma and underwent modified radical mastectomy as the definitive surgical treatment. Prior to mastectomy, locally advanced tumors were down staged in about half of the patients that received neo-adjuvant combination chemotherapy. Surgical complication rate was low. The most frequent operative complication was seroma collection in six percent of patients. The average hospital stay was ten days and most patients were followed up at the surgical outpatients department for about two years post-surgery.

Conclusions: There was low rate of mastectomy in this cohort which could partly be attributable to late presentation of many patients with inoperable local or metastatic tumors necessitating only palliative or terminal care. Tumor down-staging with neo-adjuvant chemotherapy enhanced surgical loco-regional tumor control in some patients. The overall morbidity and the rates of postoperative events were minimal. Long-term post-operative out-patients follow-up was not achieved as many patients were lost to follow up after two years of mastectomy.
\end{abstract}

Keywords: Breast cancer, Mastectomy, Nigeria

\section{Background}

Surgery is the oldest treatment modality for cancer [1]. Its role has evolved over time to include prevention, diagnosis, treatment and rehabilitation. Total colectomy for familial adenomatous polyposis coli, prophylactic mastectomy and oophorectomy in people with familial risks for breast and ovarian cancers are all examples of cancer prevention surgery. Endoscopic and open surgical biopsies enhance tissue retrieval for the all-important pathological diagnosis and characterization of solid tumors. For many solid cancers, local and regional control is achieved by total surgical extirpation, or sometimes

\footnotetext{
* Correspondence: toogundiran@yahoo.co.uk

'Division of Oncology, Department of Surgery, College of Medicine, University of Ibadan and University College Hospital, Ibadan, Nigeria ${ }^{2}$ Division of Oncology, Department of Surgery, University College Hospital, PMB 5116 Ibadan, Nigeria

Full list of author information is available at the end of the article
}

partial debulking, of the primary tumorr and the adjoining lymph nodes. Surgery is also increasingly employed in the management of solitary cancer metastases and in post treatment reconstruction and rehabilitation.

The role of surgery in the management of breast cancer consists in diagnosis, loco-regional tumor control in form of mastectomy and axillary dissection, and breast reconstruction. Vascular access for adjuvant chemotherapy and other parenteral infusions is often facilitated through outpatient surgical procedures. Furthermore, in metastatic breast cancer, surgical procedures are indicated for draining pleural effusions, stabilization bone and spine fractures and excising solitary deposits in the brain among others.

The surgical treatment of breast cancer has gone through phases. The early conservative excision gave way to Halsted's radical mastectomy and this, with its

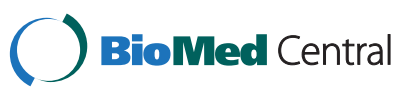


many modifications, became the traditional surgical treatment for over a century [2]. In modern times, the use of conservative surgery as part of multidisciplinary management of breast cancer is increasing throughout the world. Complete surgical removal of the breast with its local lymphatic drainage remains the preferred surgical treatment in many parts of the world, especially in low income countries (LICs) where breast conserving surgery is infrequently practiced. This is because of the late stage of presentation of most patients, the large size of tumors at diagnosis, and the aggressive nature of the disease in a predominantly young population of women [3,4]. Moreover, breast conserving surgery in LICs is faced with many challenges including logistics limitations such as paucity of radiotherapy services and inefficient followup programmes.

There have been many publications on the surgical management of breast cancer from developed countries but few from developing countries [5-8]. In this paper we present findings from a review of breast cancer patients who had mastectomy in our division over a ten year period.

\section{Methods}

We reviewed the case records of consecutive breast cancer patients who underwent mastectomy at the Surgical Oncology Division, University College Hospital (UCH) Ibadan between November 1999 and October 2009. A consultant surgeon supervised surgical residents and interns to extract data from wards admission registers, theater records and the division's operation register and histology reports of mastectomy specimens. The information from those documents was used to retrieve the patients' case files from the hospital records department. Individual patient's consent was not required for this study due to its retrospective nature and being a review of routine clinical activities. However, permission was sought from the Chairman, Medical Advisory Committee (CMAC) of the hospital who doubles statutorily as the Vice Chairman of the University of Ibadan and University College Hospital Research Ethics Committee before accessing the patients' information at the medical records department.

We recorded the patients' demographics, breast cancer diagnosis, treatment modalities and outcomes of care. All the patients had pathological confirmation of breast cancer diagnosis by either needle or open surgical biopsy. Pathological diagnosis consisted of the histological type in all the patients and immunohistochemistry in some of them. The staging investigations recorded were mainly plain chest radiograph and abdomino-pelvic ultrasonography, radionuclide bone scan was added in the latter three years of the study. The information obtained from the patients' case files were recorded in Microsoft excels spreadsheet. Descriptive methods were used to characterize the patients demography, clinical presentation, stage, treatments offered including types of mastectomy done and the outcomes of surgical treatment. Statistical analysis was done using SPSS version 15 and the results are presented in charts and graphs.

\section{Results}

We retrieved the records of 1226 newly diagnosed breast cancer patients over the study period. Of these, 431 (35.2\%) patients underwent mastectomy making an average of 43 mastectomies per year. Figure 1 shows the number of cases diagnosed and number that underwent mastectomy every year of the study. The case files of 354 patients constituting $82.1 \%$ of all mastectomies were available for review.

Table 1 shows the socio-demographic characteristics of the patients who had mastectomy. They were aged

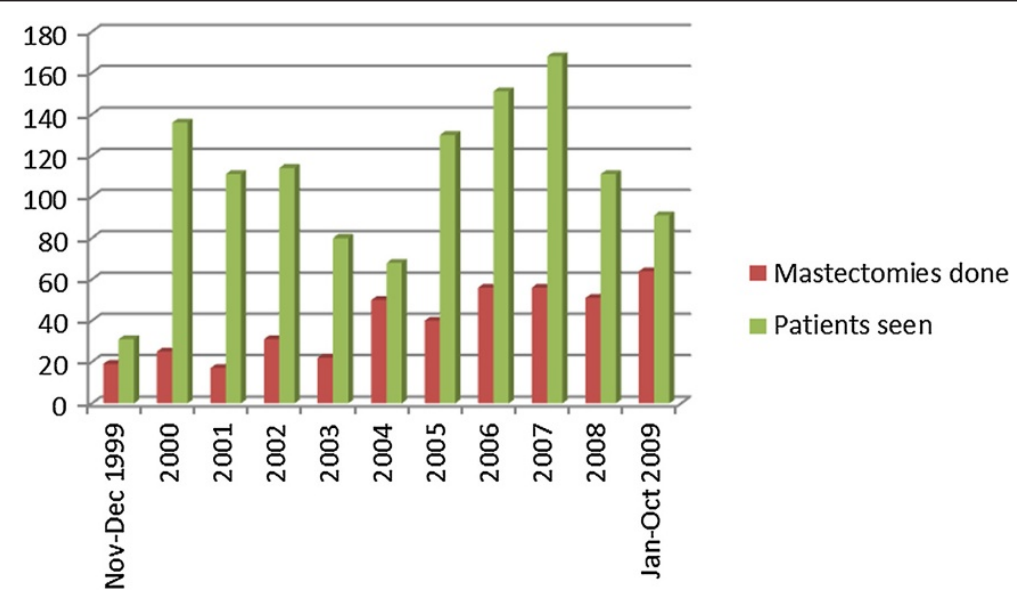

Figure 1 Numbers of breast cancer patients seen and mastectomies done per year in Surgical Oncology Division, UCH Ibadan in 1999-2009. 
Table 1 Selected characteristics of breast cancer patients who had mastectomy in Surgical Oncology Division, UCH lbadan in 1999-2009

\begin{tabular}{|c|c|c|c|}
\hline Characteristic & Mean (SD) & No $(n=354)$ & $\%$ \\
\hline Age (years) & $47.4(11.3)$ & & \\
\hline \multicolumn{4}{|l|}{ Sex } \\
\hline Male & & 14 & 3.8 \\
\hline Female & & 340 & 96.2 \\
\hline \multicolumn{4}{|l|}{ Ethnicity } \\
\hline Yoruba & & 258 & 73.0 \\
\hline Ibo & & 66 & 18.7 \\
\hline Others & & 30 & 8.3 \\
\hline \multicolumn{4}{|l|}{ Religion } \\
\hline Christianity & & 289 & 81.8 \\
\hline Islam & & 62 & 17.6 \\
\hline Others & & 3 & 0.6 \\
\hline \multicolumn{4}{|l|}{ Marital status } \\
\hline Married & & 324 & 91.5 \\
\hline Single & & 22 & 6.1 \\
\hline Others & & 8 & 2.4 \\
\hline \multicolumn{4}{|l|}{ Occupation } \\
\hline Student & & 15 & 4.3 \\
\hline Housewife & & 18 & 5.2 \\
\hline Trader & & 136 & 38.5 \\
\hline Professional & & 83 & 22.9 \\
\hline Others & & 102 & 29.1 \\
\hline Family history of breast cancer & & 18 & 5.1 \\
\hline Age at menarche & $14.9(2.20)$ & & \\
\hline Parity & $3.0(2.0)$ & & \\
\hline \multicolumn{4}{|l|}{ Menopausal status } \\
\hline Premenopausal & & 188 & 53.1 \\
\hline Postmenopausal & & 144 & 42.4 \\
\hline Not known or applicable & & 8 & 2.3 \\
\hline Height (cm) & $162(7.1)$ & & \\
\hline Weight (kg) & $63.0(15.3)$ & & \\
\hline Body mass index (kg/m2) & $24.01(4.0)$ & & \\
\hline
\end{tabular}

SD, Standard deviation.

from 20 to 76 years with a mean (SD) of 47.4(11.3) years and a median of 43 years. As expected, the majority of patients $(340,96.0 \%)$, were females. Most were Yorubas (258, 73.0\%), married (324, 91.5\%), traders (136, 38.5\%), and of the Christian religion (289, 81.8\%). Some patients $(18,5.1 \%)$ reported a family history of breast cancer. About half of the patients $(188,55.3 \%)$ were premenopausal and 144 (42.4\%) were postmenopausal. The menopausal status was not known in $8(2.3 \%)$ patients. The mean age at menarche was 14.9 (2.2) years while the mean body mass index was $24.01(4.0) \mathrm{kg} / \mathrm{m} 2$.

\section{Clinical and pathology information}

Table 2 shows the clinical and pathological characteristics of the patients. The duration of breast lump before presentation at the UCH Ibadan ranged from 1 to 84 months with a mean (SD) of 12.3(14.4) months. Breast cancer occurred in the right breast in 184 (52.2\%) patients while left sided and bilateral tumors were found in $164(46.4 \%)$ and $6(1.4 \%)$ patients respectively. Clinically, axillary node involvement was seen in $189(53.4 \%)$ patients, absent in $89(25.1 \%)$ and not stated in $76(21.5 \%)$ patients. The patients were grouped into disease stages as follows: stage I, 89 (25.0\%); stage II, 188 (55.4\%); stage III, 28 (7.8\%); and stage IV, 49 (13.8\%).

The main sites of metastasis were lung (25, 7.0\%), spine $(11,3.1 \%)$, liver $(7,2.0 \%)$ and other bones $(6,1.7 \%)$. Invasive ductal carcinoma was the commonest histological

Table 2 Clinico-pathological characteristics of breast cancer patients who had mastectomy in Surgical Oncology Division, UCH Ibadan in 1999-2009

\begin{tabular}{llll}
\hline Characteristic & Mean (SD) & No $^{*}$ & $\%$ \\
\hline Duration of breast lump (months) & $12.3(14.4)$ & & \\
Tumour side & & & \\
$\quad$ Right & & 184 & 52.2 \\
$\quad$ Left & & 164 & 46.4 \\
$\quad$ Both & & 6 & 1.4
\end{tabular}

Axillary lymph nodes involvement

Yes

$189 \quad 53.4$

No

$89 \quad 25.1$

Not stated

21.5

Distant metastasis

17.1

Site of metastasis $(n=49)$

Lung

Spine

52.2

Liver

21.7

Other bones

istology type

Invasive ductal

70.3

Others

Immunochemistry ER $(n=185)$

Positive

59.5

Negative

$110 \quad 59.5$

Immunochemistry PR $(\mathrm{n}=185)$

Positive

Negative

Immunochemistry Her 2 neu $(n=185)$

Positive

Negative

$147 \quad 79.5$

SD, Standard deviation; ${ }^{*} \mathrm{n}=354$ unless otherwise stated. 
type in 249 (70.3\%) patients. Immunohistochemistry results were available for the tumors of 185 (52.3\%) patients. Of these, 110 (59.5\%) were estrogen receptor (ER) positive, $97(52.4 \%)$ were progesterone receptor (PR) positive and 38 (20.5\%) were HER 2 positive.

\section{Adjuvant treatment}

Altogether, 315 (89.0\%) patients received anti-cancer chemotherapy. Of these, $174(49.1 \%)$ patients were treated in the neo-adjuvant setting, 127 (35.9\%) post mastectomy and 14 patients $(4.0 \%)$ both pre and post-mastectomy (Figure 2). Figures 3 and 4 respectively depicts the drug regimens and tumor response in the 174 patients that received neo-adjuvant combination chemotherapy. The anticancer drugs were sourced mainly from the hospital pharmacy and most of the patients completed 4 to 6 courses depending on the regimen used. Payment for the drugs was out-of-pocket and the choice of regimen was dictated mainly by cost and affordability by the patients. Of the 174 patients, 63 and 56 had complete and partial clinical response respectively, amounting to an overall clinical response rate of $67.7 \%$. Tumour dimensions were assessed using caliper and hand measurements, and these were corroborated with the histological reports of mastectomy specimens in some cases. The commonly administered chemotherapy regimens consisted of standard doses of $\mathrm{CMF}, \mathrm{CAF}$, and $\mathrm{AC}$ and tumor response rate by drugs is as shown in Table 3. Most of the patients received AC regime because of the shift in the unit's policy sometimes during the period of this review from a combination of CAF to AC. Further to surgery and chemotherapy, 212 (67.0\%) and 119 (37.7\%) patients received adjuvant radiotherapy and hormonal therapy respectively. Hormonal therapy consisted mainly of daily dose of $20 \mathrm{mg}$ tamoxifen for at least 2 years.

\section{Surgical treatment}

Modified radical mastectomy was the surgical treatment in $342(96.7 \%)$ patients (Table 4). This consisted of excising the whole breast tissue off the chest wall including the axillary tail and complete axillary clearance of lymph nodes and connective tissue up to level 3 by generous retraction of the pectoralis minor muscle. Where involved, a portion of the underlying muscle was excised in continuity with the breast tissue. A few patients, 7 (2.1\%), were offered quadrantectomy and axillary clearance. The type of surgical procedure performed was not stated in $5(1.2 \%)$ patients. The mode of anesthesia was general anesthesia in $293(82.7 \%)$ patients, local infiltration in $11(3.0 \%)$ patients and not stated in 50 (14.3\%) patients. Most mastectomies, 239 (67.5\%), were done by consultant surgeons while the rest were performed by resident surgeons. About a quarter of the patients received perioperative blood transfusion, 53 (14.9\%) during surgery and 35 (10.0\%) post-operatively. All the patients transfused were those with either T3 or T4 tumors at presentation and the mean number of blood units transfused was 1.9 units. The mastectomy wounds were drained using close passive drain in 315 (88.7\%) patients, close active (suction) drain in 19 (5.4\%) patients and unknown in 20 (5.9\%) patients.

\section{Post-operative care and follow up}

Post-operative complications within 30 days of surgery occurred in 51 (14.5\%) patients with seroma accumulation under the skin flap ranking highest in 21 (6.0\%) of the patients. Surgical wound infection occurred in 16 $(4.4 \%)$ and skin flap necrosis in $6(1.7 \%)$ patients. Other less common post-operative events in 8 (2.3\%) patients included shoulder joint stiffness and paraesthesia of the upper arm (Figure 5). The surgical drains were removed between the 8 th and 14th postoperative day with a mean of 10 days. The wound drains were removed when the output was clear or straw coloured and less than $40 \mathrm{mls}$ in the preceding $24 \mathrm{hr}$ period. None of the patients was discharged home with the drain. The least and maximum duration of hospital stay from admission for mastectomy to discharge post-operatively was 9 days and

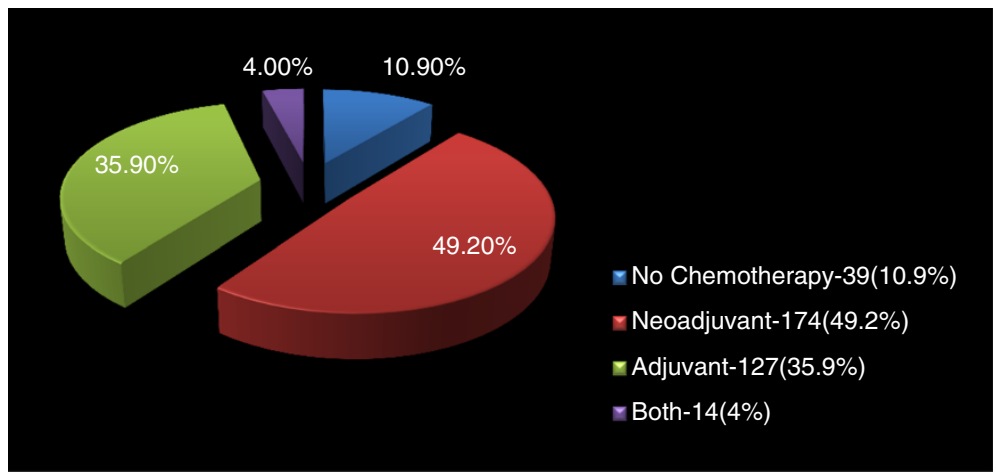

Figure 2 Distribution of administration of chemotherapy in 354 patients who had mastectomy in Surgical Oncology Division, UCH Ibadan in 1999-2009. 


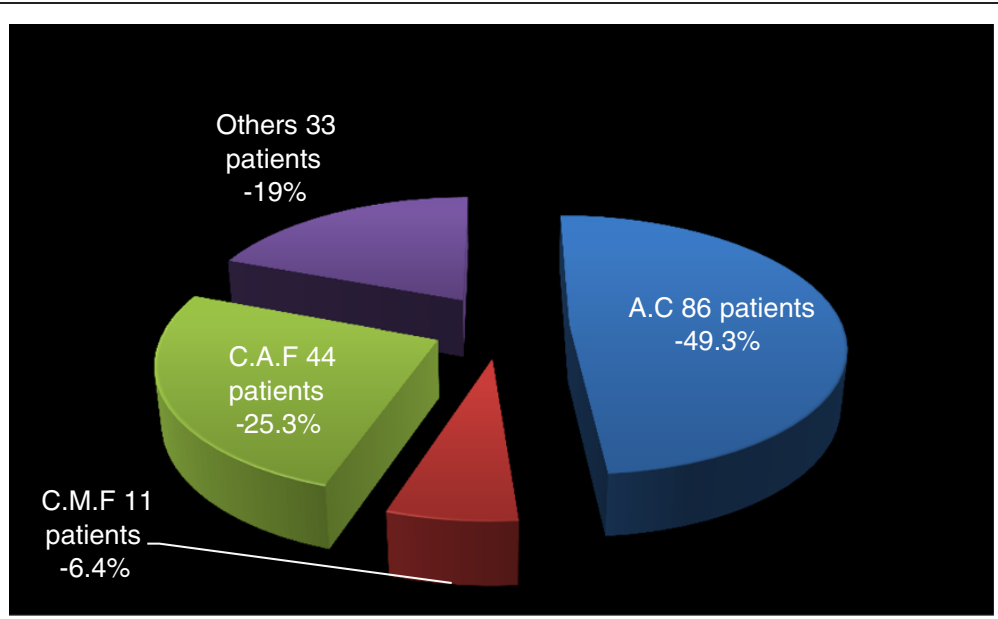

Figure 3 Neo-adjuvant chemotherapy regimens in 174 pre-mastectomy patients in Surgical Oncology Division, UCH Ibadan in 1999-2009.

15 days with a mean (SD) of 12 days. Most patients were seen at the surgical outpatients department for follow up care for less than 2 years. At 18 months, $37.9 \%$ of the patients were still attending the outpatients clinics, followed thereafter by a gradual decline with most patents lost to follow up between the 24th and 30th months post mastectomy.

\section{Discussion}

In this review, most patients were young women, premenopausal, had invasive ductal carcinoma and underwent modified radical mastectomy as the definitive surgical treatment. Prior to mastectomy, the tumor was down staged in half of the patients that received neo-adjuvant combination chemotherapy. About two-thirds and a third of all the patients received post-operative radioand hormonal therapy respectively. The most frequent operative complication was seroma collection in six percent of the patients. The average hospital stay was ten days and most patients were followed up at the surgical outpatients department for about two years post surgery.

Surgery remains an important and essential component of the management of breast cancer, the increasing availability and utilization of adjuvant therapies notwithstanding. In the period under review however, only about one third of the patients with breast cancer received surgical treatment. This breast cancer surgery (BCS) rate was low compared to findings from a similar review in New Zealand where $58.6 \%$ of their patients over a 5 year period had BCS [7]. The reasons that possibly contributed to the low mastectomy rate in our patients include late presentation with inoperable local or metastatic tumours necessitating only palliative or terminal care, inability to pay out-of-pocket for treatment,

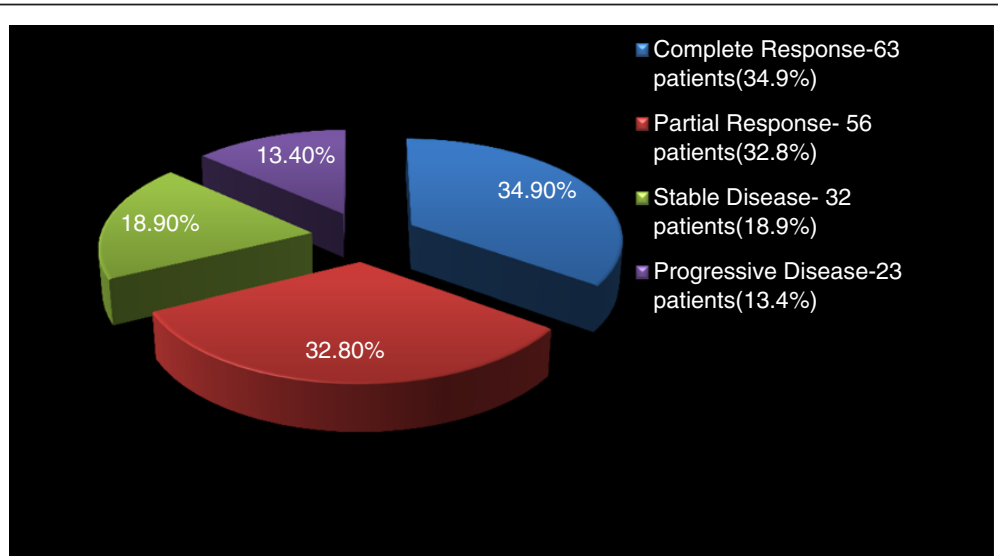

Figure 4 Tumour responses to neo-adjuvant chemotherapy in 174 pre-mastectomy patients in Surgical Oncology Division, UCH Ibadan in 1999-2009. 
Table 3 Responses to neo-adjuvant chemotherapy regimens in 174 pre-mastectomy patients in Surgical Oncology Division, UCH Ibadan in 1999-2009

\begin{tabular}{llllll}
\hline & Complete response & Partial response & Stable disease & Disease progression & Total (\%) \\
\hline AC & $34(18.8 \%)$ & $29(16.9 \%)$ & $16(9.5 \%)$ & $7(4.1 \%)$ & $86(49.3)$ \\
CAF & $16(8.8 \%)$ & $11(6.5 \%)$ & $11(6.5 \%)$ & $6(3.5 \%)$ & $44(25.3)$ \\
CMF & $4(2.3 \%)$ & $5(2.9 \%)$ & - & $2(1.2 \%)$ & $11(6.4)$ \\
Others. & $9(5.0 \%)$ & $11(6.5 \%)$ & $5(2.9 \%)$ & $8(4.6 \%)$ & $33(19.0)$ \\
Total $(\%)$ & $63(34.9 \%)$ & $56(32.8 \%)$ & $32(18.9 \%)$ & $23(13.4 \%)$ & $174(100)$ \\
\hline
\end{tabular}

A, Adriamycin; C, Cyclophosphamide; F, 5-Fluorouracil; M, Methotrexate.

and unwillingness to have mastectomy with consequent loss to follow up [9].

The pattern of clinical presentation and histological types seen in these patients were similar to earlier reports from Nigeria and the West African sub-region [3,10-12]. Breast cancer in many developing countries is characterized by late presentation, younger age at diagnosis, large

Table 4 Surgical and peri-operative care of mastectomy patients in Surgical Oncology Division, UCH Ibadan in 1999-2009

\begin{tabular}{|c|c|c|}
\hline Characteristic & $\mathrm{No}^{*}$ & $\%$ \\
\hline \multicolumn{3}{|l|}{ Type of mastectomy } \\
\hline Modified radical mastectomy & 342 & 96.7 \\
\hline Quadrantectomy & 7 & 2.1 \\
\hline Not stated & 5 & 1.2 \\
\hline \multicolumn{3}{|l|}{ Mode of anaesthesia } \\
\hline General anaesthesia & 293 & 82.7 \\
\hline Local infiltration & 11 & 3.0 \\
\hline Not stated & 50 & 14.1 \\
\hline \multicolumn{3}{|l|}{ Cadre of Surgeon } \\
\hline Consultant & 239 & 67.5 \\
\hline Resident & 115 & 32.5 \\
\hline \multicolumn{3}{|l|}{ Blood transfusion $(n=88)$} \\
\hline Intraoperative & 53 & 14.9 \\
\hline Postoperative & 35 & 10.0 \\
\hline Mean number of units & 1.9 & \\
\hline \multicolumn{3}{|l|}{ Types of drain } \\
\hline Passive & 315 & 88.7 \\
\hline Suction & 19 & 5.4 \\
\hline Unknown & 20 & 5.9 \\
\hline \multicolumn{3}{|l|}{ Postoperative complications ( $n=51$ ) } \\
\hline Seroma & 21 & 6.0 \\
\hline Wound infection & 16 & 4.4 \\
\hline Flap necrosis & 6 & 1.7 \\
\hline Others & 8 & 2.3 \\
\hline Mean hospital stay (days) & 12 & \\
\hline Follow up at 18 months post mastectomy & & 37.9 \\
\hline
\end{tabular}

${ }^{*} \mathrm{n}=354$ unless otherwise stated. tumours and multiple nodal involvements. A recent survey in Lagos, a nearby city showed that more than fourfifths of the patients delayed for 3 months before the initial medical consultation [13]. The pattern of presentation differs from that in the western world where most patients are post-menopausal and present with small sized early tumors and less aggressive disease. This is more a reflection of the differences in the demographic pattern of these societies than of assumed differences in the intrinsic biology of the disease in the two populations $[10,14,15]$. The predominance of invasive ductal carcinoma is also akin to what is seen in other parts of the world.

Although immunohistochemistry was obtained in only half of these patients, its pattern nonetheless, tallies with what has been previously reported from our group in the same cohort of patients [16]. About two-thirds of the tumors had either estrogen or progesterone receptor positivity and one-fifth of them were Her2 neu positive. Previous immunohistochemistry reports had suggested that breast cancer tumors in Africans were estrogen or progesterone receptor poor $[17,18]$. These findings were unreflective of the true picture given that those studies were done on old archival tissues in which antigen degradation had occurred $[19,20]$. Our findings are similar to values from other populations, including from within Africa, and further support our earlier conclusion that the pattern of hormone receptors in breast cancer patients of African origin does not differ from others [16,21-23].

More than half of our patients with locally advanced cancer had positive tumour response and down staging by the use of adjuvant chemotherapy. This supports the role of neo adjuvant chemotherapy in our patients in whom one in every two patients with advanced disease can be down staged thus enhancing the prospects of loco-regional surgical tumor extirpation. A previous report from Eastern Nigeria had documented a response rate of $81 \%$ in 32 women with locally advanced breast cancer who received neo-adjuvant combination CAF chemotherapy [24]. Since its inception in the early 1970s, systemic chemotherapy as an adjunct to surgery has emerged as the foremost conceptual change in the treatment of 


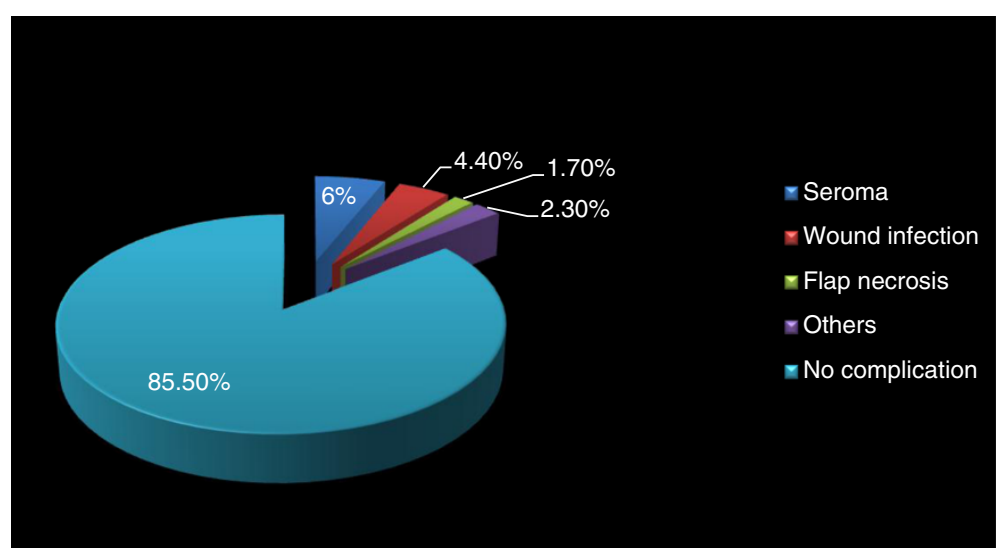

Figure 5 Complications of mastectomy in 51/354 breast cancer patients in Surgical Oncology Division, UCH Ibadan in 1999-2009.

breast cancer [25]. It also improves overall survival in both younger and older women with node positive breast cancer [26]. Anthracycline based combination chemotherapy was the most commonly used regimen in our patients, and this had been shown to reduce primary tumour burden by at least $50 \%$ as far back as the pre-taxanes era [25]. Moreover, our patients received adjuvant radiation and hormonal therapies as indicated as part of standard anticancer treatment. Radiation therapy consisted mainly of post mastectomy chest wall irradiation and irradiation of localized secondary deposits in the spine, in long bones and the brain when indicated. Documentation problems in patients' case files most probably account for the apparently low rate of hormonal therapy in the patients.

The surgical option in almost all patients was modified radical mastectomy (MRM). This still remains the standard surgical operation for operable breast cancer in most parts of the world. The indications for MRM in our patients were early breast cancer (stages I and II), locally advanced disease pre- or post-adjuvant treatment and in select patients with metastatic disease who required local control post systemic therapy. Only a negligible number of our patients had breast conserving surgery (BCS). Early presentation and the availability and extensive use of adjuvant therapies have made BCS to gain widespread usage in some parts of the world $[27,28]$. This is especially so in developed countries where evidence now abounds that it is as effective as MRM in early breast cancer $[2,29]$. Though a feasible option in some patients, BCS is likely to remain an infrequent surgical treatment for breast cancer in many low income settings for a long time to come. This is because most patients present late for treatment and more often with poor grade tumours. Moreover, there are limitations that are imposed by logistics such as paucity of radiotherapy services and inefficient follow-up programmes. The inability of patients to follow through post-surgery treatment schedules due to low literacy levels and poverty contribute to these challenges. Although sentinel lymph node (SLN) biopsy has become the preferable standard to axillary dissection in breast cancer surgery, this was not done in any of our patients. Going forward from this review, and with the requisite expertise acquired, new patients that present with no palpable lymph nodes and those with good response to neo-adjuvant chemotherapy will be considered for this procedure. This would hopefully reduce needless axillary clearance and its attendant risks and complications.

Almost a quarter of the patients received blood transfusion either during surgery or in the post-operative period and transfusion occurred only in those with locally advanced tumours. Perioperative blood transfusion in breast cancer patients had been a subject of study in the past decade with some suggesting that blood transfusion had harmful effects on outcome [30-32] and others failing to support such notion [33,34]. Perioperative blood usage was high in our patients. This contrasts with a 2 year British hospital audit spanning 2004/5 in which the transfusion rate was $3.8 \%$ for mastectomy and $20.0 \%$ for mastectomy with immediate breast reconstruction [35]. Though not stated in that report, the clinicopathological pattern and prognostic indicators in their patients were likely to be more favourable given that most of them were likely to present early for treatment. The use of blood transfusion in the first and second halves of our study period did not show a remarkable difference. However, in our current experiences perioperative blood usage is significantly minimal. This may partly be due to our current standard use of neo-adjuvant treatment to downstage the tumor in locally advanced breast cancer.

Ezeome and Adebamowo had earlier reported that closed simple drains were cheap, simple to manage and effectively comparable to closed suction drains for mastectomy wounds [36]. These characteristics make closed 
passive drain the more attractive option for breast cancer surgery in low income countries and explain why this was predominantly used in our patients. In the study by Ezeome and Adebamowo, a higher wound infection rate was associated with passive tube drains compared to suction drains. In our current review, however, the infection rate was similar to what had been reported from other studies where closed suction drains were predominantly used [32,37]. Akin to the discussion on types of drain is consideration of the length of drainage and the duration of in-patient care after mastectomy. The length of drainage seems to be directly proportional to the duration of postoperative in-hospital care. The standard management of mastectomy drain was to remove the drain when drainage was minimal, usually less than $40 \mathrm{ml}$ over a 24-hour period or after 12-14 days whichever came first [37]. This protocol kept the patient in hospital for an average of 8 to 10 days and increased the hospital bill significantly. Some studies compared this protocol with a policy of either no drain at all or early drain removal and early postoperative discharge from the hospital. The results recorded were shorter hospital stay, no difference in surgical or psychological morbidity and significant cost savings [37-39]. Our drain policy is still evolving but the present practice is to admit patients on the day before surgery, review their wound on the 5th postoperative day and discharge them as soon as the drain can be removed thereafter.

The overall morbidity and the rates of postoperative events in our cohort compare favorably with what have been variously reported in literature. Seroma accumulation under the skin flap was the commonest complication as has been documented in many series [8,40-42]. Factors that have been associated with seroma formation include large dead space, irregularity of chest wall, low concentration of endostatin (an anti-angiogenic factor), use of electrocautery for flap dissection compared to scalpel and modified radical mastectomy compared to breast conserving mastectomy $[8,42]$. In a pooled analysis of prospectively enrolled 3107 women who had mastectomy in 18 hospitals over a 3 year period, EtTamer et al. reported an overall wound infection rate of $4.3 \%{ }^{8}$ The rate of infection in our series tallies closely with theirs. Moreover, mastectomy was associated with more wound issues than conservative surgery in their series. A little above a third of the patients were attending the surgical outpatients department 24 months after mastectomy. The reasons for loss of many to long time follow up are not known, thus the survival pattern in this cohort might never be determined. However, a previous Nigerian study reported a median survival of 31 months with survival advantage for post-menopausal women and in those with early stage disease [43].

\section{Conclusions}

Modified radical mastectomy remains the standard therapeutic surgical operation for breast cancer in Nigeria. Though many patients present late for treatment, tumor down-staging with neo-adjuvant chemotherapy enhances surgical loco-regional tumor control in some of them. The overall morbidity and the rates of postoperative events are minimal and comparable to what obtain in other parts of the world. However, long-term follow-up is still a challenge as many patients are lost to follow up after two years of mastectomy. This review has limitations due to its retrospective nature. The case notes of some of the patients that had mastectomy were not available for review as at the time of the study. Moreover some data were missing from some case notes such that the denominator was not uniform for all the variables that were analyzed. Furthermore, the pattern of survival of the patients post-mastectomy cannot be determined because of inadequate follow up records and information.

\section{Competing interests}

The authors declare that they have no competing interests.

\section{Authors' contributions}

TO participated in patients' management, conceived the study, coordinated and co-wrote the manuscript. OA participated in patients' management, study design and co-wrote the manuscript. AA participated in patients' management and study design. CA participated in patients' management, study design and co-wrote the manuscript. All authors read and approved the final manuscript.

\section{Acknowledgements}

The authors thank the surgical residents and interns who assisted in extracting the data for this work. This project was partly supported by Grant Number D43TW009106 from the Fogarty International Center. The contents are solely the responsibility of the authors and do not necessarily represent the official views of the Fogarty International Center of the National Institutes of Health.

\section{Author details}

${ }^{1}$ Division of Oncology, Department of Surgery, College of Medicine, University of Ibadan and University College Hospital, Ibadan, Nigeria. 2Division of Oncology, Department of Surgery, University College Hospital, PMB 5116 Ibadan, Nigeria. Institute of Human Virology, Abuja, Nigeria. ${ }^{4}$ Department of Epidemiology and Preventive Medicine, University of Maryland, Maryland, USA.

Received: 13 May 2013 Accepted: 10 December 2013 Published: 19 December 2013

\section{References}

1. Holland-Frei Cancer Medicine 6. 6th edition. Edited by Kufe DW, Pollock RE, Weichselbaum RR. Hamilton, Ontario, Canada: BC Decker; 2003.

2. Zurrida S, Bassi F, Arnone P, et al: The changing face of mastectomy (from mutilation to Aid to breast reconstruction). Int J Surg Oncol 2011, 2011:980158.

3. Adebamowo CA, Ajayi OO: Breast cancer in Nigeria. West Afr J Med 2000, 19:179-191.

4. El Saghir NS, Adebamowo CA, Anderson BO, et al: Breast cancer management in low resource countries (LRCs): consensus statement from the breast health global initiative. Breast 2011, 20(Suppl 2):S3-S11.

5. Broadwater JR, Edwards MJ, Kuglen C, Hortobagyi GN, Ames FC, Balch CM: Mastectomy following preoperative chemotherapy. Strict operative criteria control operative morbidity. Ann Surg 1991, 213:126-129. 
6. Grilli R, Mainini F, Penna A, et al: Inappropriate Halsted mastectomy and patient volume in Italian hospitals. Am J Public Health 1993, 83:1762-1764.

7. Lee DW, Vallance S: Surgical management of breast cancer in a small peripheral New Zealand hospital. ANZ J Surg 2006, 76:1060-1063.

8. El-Tamer MB, Ward BM, Schifftner T, Neumayer L, Khuri S, Henderson W: Morbidity and mortality following breast cancer surgery in women: National benchmarks for standards of care. Ann Surg 2007, 245:665-671.

9. Anyanwu SN, Egwuonwu OA, Ihekwoaba EC: Acceptance and adherence to treatment among breast cancer patients in Eastern Nigeria. Breast 2011, 20(Suppl 2):S51-S53.

10. Adebamowo CA, Adekunle OO: Case-controlled study of the epidemiological risk factors for breast cancer in Nigeria. Br J Surg 1999, 86:665-668

11. Clegg-Lamptey JN, Dakubo JC, Hodasi WM: Comparison of four-day and ten-day post- mastectomy passive drainage in Accra, Ghana. East Afr Med J 2007, 84:561-565.

12. Clegg-Lamptey J, Hodasi W: A study of breast cancer in korle bu teaching hospital: assessing the impact of health education. Ghana Med J 2007 41:72-77.

13. Ibrahim NA, Oludara MA: Socio-demographic factors and reasons associated with delay in breast cancer presentation: a study in Nigerian women. Breast 2012, 21:416-418.

14. Anders CK, Johnson R, Litton J, Phillips M, Bleyer A: Breast cancer before age 40 years. Semin Oncol 2009, 36:237-249.

15. Bird PA, Hill AG, Houssami N: Poor hormone receptor expression in East African breast cancer: evidence of a biologically different disease? Ann Surg Oncol 2008, 15:1983-1988.

16. Adebamowo CA, Famooto A, Ogundiran TO, Aniagwu T, Nkwodimmah C, Akang EE: Immunohistochemical and molecular subtypes of breast cancer in Nigeria. Breast Cancer Res Treat 2008, 110:183-188.

17. Gukas ID, Jennings BA, Mandong BM, et al: Clinicopathological features and molecular markers of breast cancer in Jos, Nigeria. West Afr J Med 2005, 24:209-213.

18. Ikpatt OF, Kuopio T, Ndoma-Egba R, Collan Y: Breast cancer in Nigeria and Finland: Epidemiological, clinical and histological comparison. Anticancer Res 2002, 22:3005-3012.

19. Bertheau P, Cazals-Hatem D, Meignin V, et al: Variability of immunohistochemical reactivity on stored paraffin slides. J Clin Pathol 1998, 51:370-374

20. Olapade-Olaopa EO, MacKay EH, Habib FK: Variability of immunohistochemical reactivity on stored paraffin slides. J Clin Pathol 1998, 51:943.

21. Murray E: Breast cancer clinic at Groote Schuur Hospital. In AORTIC Newsletter. South Africa: AORTIC; 2005:10-1.

22. Middleton LP, Chen V, Perkins GH, Pinn V, Page D: Histopathology of breast cancer among African-American women. Cancer 2003, 97:253-257.

23. Nichols HB, Trentham-Dietz A, Love RR, et al: Differences in breast cancer risk factors by tumor marker subtypes among premenopausal Vietnamese and Chinese women. Cancer Epidemiol Biomarkers Prev 2005, 14:41-47.

24. Anyanwu SN, Nwose P, Ihekwoaba E, Mbaeri AT, Chukwuanukwu TO: Neoadjuvant chemotherapy for locally advanced premenopausal breast cancer in Nigerian women: early experience. Niger J Clin Pract 2010, $13: 215-217$

25. Schwartz GF, Hortobagyi GN: Proceedings of the consensus conference on neoadjuvant chemotherapy in carcinoma of the breast, April 26-28, 2003, Philadelphia, Pennsylvania. Cancer 2004, 100:2512-2532.

26. Muss HB, Woolf $\mathrm{S}$, Berry D, et al: Adjuvant chemotherapy in older and younger women with lymph node-positive breast cancer. JAMA 2005, 293:1073-1081.

27. Lee S, Kim SW, Kim SK, et al: Locoregional recurrence of breast conserving surgery after preoperative chemotherapy in korean women with locally advanced breast cancer. J Breast Cancer 2011, 14:289-295.

28. Jatol I: Options in breast cancer local therapy: who gets what? World J Surg 2012, 36:1498-1502.

29. Litiere $S$, Werutsky $G$, Fentiman IS, et al: Breast conserving therapy versus mastectomy for stage I-II breast cancer: 20 year follow-up of the EORTC 10801 phase 3 randomised trial. Lancet Oncol 2012, 13:412-419.

30. Pysz M: Blood transfusions in breast cancer patients undergoing mastectomy: Possible importance of timing. J Surg Oncol 2000, 75:258-263.
31. Aslan S, Akinci M, Cetin B, Cakmak H, Pirhan Y, Cetin A: Postoperative changes related to intraoperative blood transfusions. Bratis/ Lek Listy 2011, 112:575-578.

32. Leinung $S$, Schonfelder M, Winzer $\mathrm{KJ}$, et al: Wound infection and infectionpromoting factors in breast cancer surgery - a prospective multicenter study on quality control. Zentralb/ Chir 2005, 130:16-20.

33. Eickhoff JH, Andersen J, Laybourn C: Perioperative blood transfusion does not promote recurrence and death after mastectomy for breast cancer. The Danish breast cancer cooperative group. Br J Surg 1991 78:1358-1361

34. Akyol AM, Galloway DJ, George WD: Perioperative blood transfusion does not promote recurrence and death after mastectomy for breast cancer. Br J Surg 1992, 79:470.

35. Malik H, Bishop H, Winstanley J: Audit of blood transfusion in elective breast cancer surgery-do we need to group and save pre-operatively? Ann R Coll Surg Engl 2008, 90:472-473.

36. Ezeome ER, Adebamowo CA: Closed suction drainage versus closed simple drainage in the management of modified radical mastectomy wounds. S Afr Med J 2008, 98:712-715.

37. Edwards MJ, Broadwater JR, Bell JL, Ames FC, Balch CM: Economic impact of reducing hospitalization for mastectomy patients. Ann Surg 1988, 208:330-336.

38. Purushotham AD, McLatchie E, Young D, et al: Randomized clinical trial of no wound drains and early discharge in the treatment of women with breast cancer. Br J Surg 2002, 89:286-292.

39. Tarazi R, Esselstyn CB Jr, Kuivila T, Hardesty I: Early hospital discharge following mastectomy. Cleve Clin Q 1984, 51:579-584.

40. Wedgwood KR, Benson EA: Non-tumour morbidity and mortality after modified radical mastectomy. Ann R Coll Surg Engl 1992, 74:314-317.

41. Yilmaz KB, Dogan $L$, Nalbant $H$, et al: Comparing scalpel, electrocautery and ultrasonic dissector effects: the impact on wound complications and pro-inflammatory cytokine levels in wound fluid from mastectomy patients. J Breast Cancer 2011, 14:58-63.

42. Kuroi K, Shimozuma K, Taguchi T, et al: Pathophysiology of seroma in breast cancer. Breast Cancer 2005, 12:288-293.

43. Anyanwu SN: Survival following treatment of primary breast cancer in eastern Nigeria. East Afr Med J 2000, 77:539-543.

doi:10.1186/1471-2482-13-59

Cite this article as: Ogundiran et al:: Mastectomy for management of breast cancer in Ibadan, Nigeria. BMC Surgery 2013 13:59.

\section{Submit your next manuscript to BioMed Central and take full advantage of:}

- Convenient online submission

- Thorough peer review

- No space constraints or color figure charges

- Immediate publication on acceptance

- Inclusion in PubMed, CAS, Scopus and Google Scholar

- Research which is freely available for redistribution
C) Biomed Central 